\title{
Bone metastasis of esophageal carcinoma diagnosed as a first primary tumor: a population-based study
}

\author{
Rong-Chun Wang ${ }^{1 \#}$, Xiao-Long Liu ${ }^{2 \#}$, Chen $\mathrm{Qi}^{1}$, Hao Chen ${ }^{2}$, Yi-Yang Liu ${ }^{2}$, De-Min Li ${ }^{1}$, Hai-Zhu Song ${ }^{3}$, \\ Jun $\mathbf{Y i}^{1}$
}

${ }^{1}$ Department of Cardiothoracic Surgery, Affiliated Jinling Hospital, Medical School of Nanjing University, Nanjing, China; ${ }^{2}$ Department of Cardiothoracic Surgery, Jingling Hospital, Jingling School of Clinical Medicine, Nanjing Medical University, Nanjing, China; ${ }^{3}$ Department of Medical Oncology, Affiliated Jinling Hospital, Medical School of Nanjing University, Nanjing, China

Contributions: (I) Conception and design: RC Wang, XL Liu, J Yi; (II) Administrative support: J Yi, DM Li, HZ Song; (III) Provision of study materials or patients: RC Wang; (IV) Collection and assembly of data: YY Liu, H Chen; (V) Data analysis and interpretation: C Qi; (VI) Manuscript writing: All authors; (VII) Final approval of manuscript: All authors.

\#These authors contributed equally to this work.

Correspondence to: Jun Yi, PhD. Department of Cardiothoracic Surgery, Affiliated Jinling Hospital, Medical School of Nanjing University, Nanjing, China. Email: drjunyi@126.com.

Background: This study aimed to explore predictors of bone metastasis (BM) of esophageal carcinoma (EC) and factors affecting the prognosis of EC with BM (ECBM).

Methods: We retrospectively studied the data of EC patients from the Surveillance, Epidemiology, and End Results (SEER) database between 2010 and 2016. Logistic regression analysis was used to analyze the risk factors of BM. Cox regression and Fine and Gray's competing risk regression were performed to identify prognostic factors associated with all-cause and cancer-specific death, respectively. The Kaplan-Meier method was used to assess survival.

Results: After exclusion, 8,916 patients were eligible, of whom 462 (5.2\%) had ECBM. Independent risk factors of BM were age < 65 years, male sex, stage T1, advanced $\mathrm{N}$ stage, and non-bone organ metastases. For EC, the median survival time (MST) was 17 months, and the 3-and 5-year survival rates were $31.6 \%$ and $23.3 \%$, respectively; meanwhile, for BM, the MST was 5 months, and the 3 - and 5 -year survival rates were $2 \%$ and $1 \%$, respectively. Adenocarcinoma, stage T2, the absence of non-bone organ metastases, and combined radiotherapy and chemotherapy were associated with a reduced risk of all-cause death in ECBM patients. Stage T2, the absence of non-bone organ metastases, and combined radiotherapy and chemotherapy were associated with a decreased risk of cancer-specific death in ECBM patients.

Conclusions: Although rare, BM severely impairs the prognosis of EC. BM predictors and factors influencing the prognosis of ECBM may help distinguish high-risk patients with BM and assess survival in ECBM patients.

Keywords: Bone metastasis (BM); esophageal carcinoma (EC); Surveillance, Epidemiology, and End Results (SEER); survival; chemoradiotherapy

Submitted Sep 29, 2021. Accepted for publication Nov 24, 2021.

doi: $10.21037 /$ tcr-21-2104

View this article at: https://dx.doi.org/10.21037/tcr-21-2104

\section{Introduction}

According to global cancer statistics published in 2021, last year the incidence of esophageal carcinoma (EC) ranks eighth, with an increase of approximately 600,000 individuals, and the mortality rate ranks sixth, with approximately 540,000 deaths (1). Asian countries, especially China, are deeply troubled by EC because its prognosis is poor (2). In addition, the 5 -year survival rate in patients with 


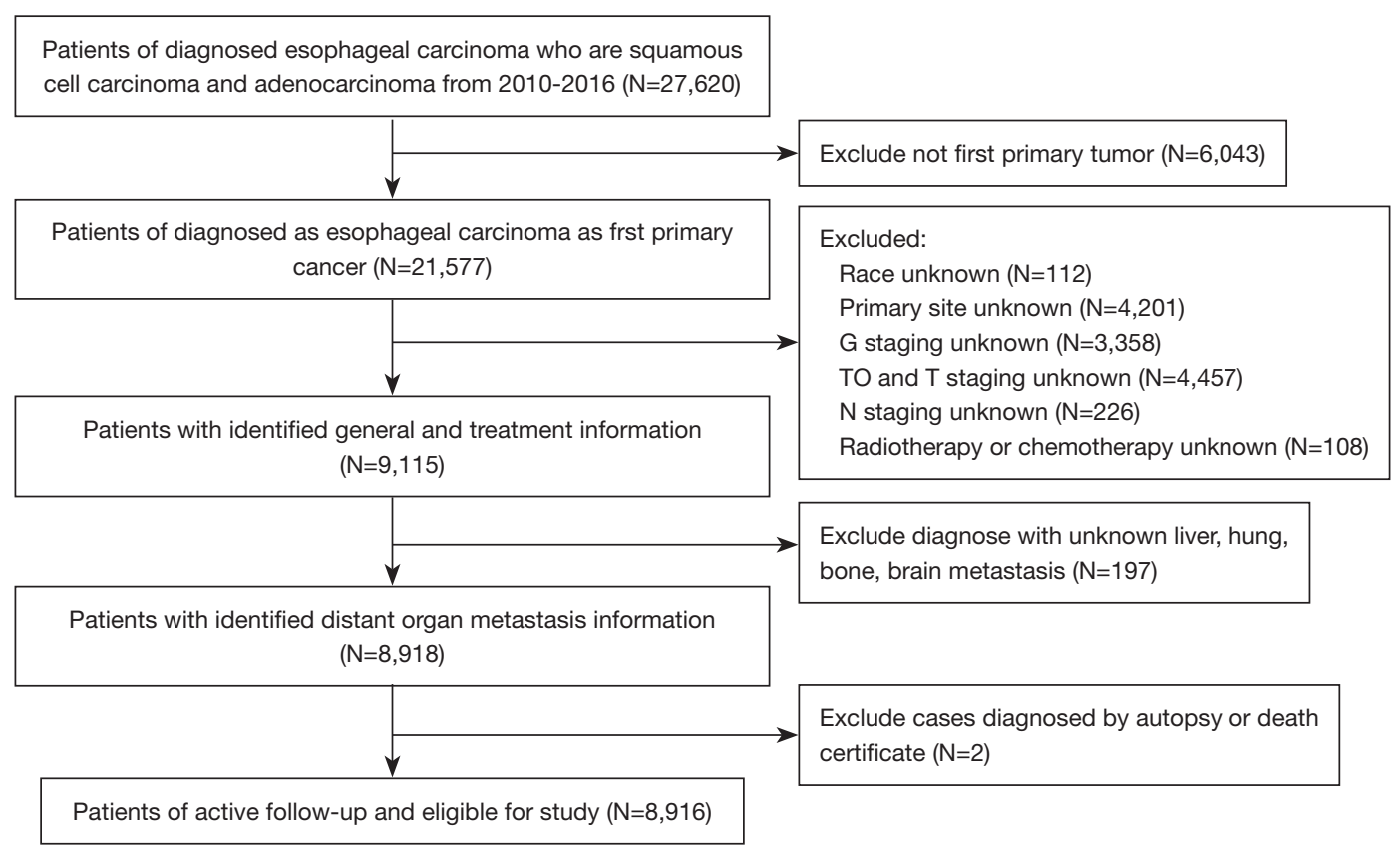

Figure 1 Flowchart of esophageal carcinoma patients screening from the SEER database.

distant metastases is notably lower, at less than $5 \%$ (3). Approximately $40 \%$ of the patients are found to have distant metastases on receiving a diagnosis of EC (4), and nearly onethird of the patients develop distant metastases after surgery or chemoradiotherapy (5). Distant metastases have become an annoying stumbling block resulting in the treatment failure of EC. Therefore, it is essential to gain a profound understanding of the patterns of distant metastasis of EC.

A study based on the Surveillance, Epidemiology, and End Results (SEER) database showed that the sites of distant metastases of EC in the order of incidence are as follows: liver (15.6\%), lungs (9.7\%), bone (7.7\%), and brain (1.6\%) (6). Due to their high incidence, liver and lung metastases have been described in detail in recent reports $(7,8)$. However, bone metastasis $(\mathrm{BM})$ is more common in breast and prostate cancer and relatively rare in EC; thus, the metastasis pattern of EC with BM (ECBM) remains unclear. Although ECBM has been reported previously based on the SEER database, the study population included patients in whom EC was not the first primary tumor. Moreover, the study lacked information on therapy and did not remove the competing risks of non-cancer-related deaths (9). Based on the SEER database, we explored the risk factors of $\mathrm{BM}$ in first primary $\mathrm{EC}$ and analyzed the factors influencing the prognosis of ECBM patients. We present the following article in accordance with the
STROBE reporting checklist (available at https://tcr. amegroups.com/article/view/10.21037/tcr-21-2104/rc).

\section{Methods}

\section{Study population selection}

The SEER database is a comprehensive tumor database established by the National Cancer Institute. It covers more than $30 \%$ of the population in the United States from 18 registries, which includes information on demographic characteristics, staging, treatment, and follow-up. Through online application, the required data can be extracted from SEERStat 8.3.9. We selected the incidence data from 18 registration centers with additional treatment fields and selected 2010-2016 data of esophageal squamous cell carcinoma and adenocarcinoma because the SEER database has included patients' metastatic site information since 2010. The exclusion criteria were as follows: (I) patients in whom EC was not the first primary tumor; (II) patients with unknown information on treatment, staging, and metastases; and (III) patients with EC diagnosed based on autopsy or a death certificate. A detailed screening flowchart is presented in Figure 1. The primary tumor site was categorized as the upper, middle, and lower segments based on the location of the tumor center. The upper segment included the cervical esophagus (code: C15.0) and upper third of the esophagus 
(code: C15.3), the middle segment contained the middle third of the esophagus (code: C15.4), and the lower segment included the lower third of the esophagus (code: C15.5) and abdominal esophagus (code: C15.2). Tumors in overlapping positions were considered unknown sites and excluded. Tumor-node-metastasis (TNM) staging was classified according to the 7 th edition of the TNM classification. Tumor size could not be included as a variable in this study due to a large amount of missing data.

\section{Statistical analysis}

Univariate and multivariate logistic regression analyses were performed to explore the predictors of BM in EC patients. The survival time and survival rate were determined using Kaplan-Meier curves with log-rank tests. Given that different causes of death were considered different endpoint events, the causes of death were classified into two categories: allcause and cancer-specific. Univariate and multivariate Cox regression analyses were conducted to identify factors related to all-cause death. Univariate and multivariate Fine and Gray's competing risk regression analyses were performed to analyze factors associated with cancer-specific death.

Continuous variables are expressed as mean \pm standard deviation, and categorical variables are expressed as frequencies or percentages. For categorical variables, the data between the two groups were compared using the Pearson's chi-squared test or Fisher's exact test. For continuous variables, the data were compared using an unpaired $t$-test or Mann-Whitney $\mathrm{U}$ test. All analyses were performed using R software version 3.4.3 (R Foundation for Statistical Computing, Vienna, Austria) and SPSS 23 (IBM Corporation, Armonk, NY, USA). GraphPad Prism 8 was used to plot the data. Two-sided $\mathrm{P}<0.05$ was considered statistically significant.

\section{Ethical statement}

The study was conducted in accordance with the Declaration of Helsinki (as revised in 2013). Since all the data used in the study were from public databases, the requirement to obtain informed consent from the patients was exempted.

\section{Results}

\section{Demographic characteristics}

The data of 27,620 EC patients were extracted from the SEER database between 2010 and 2016, of which 6,043 patients in whom EC was not the first primary tumor were excluded. After applying a series of exclusion criteria, 8,916 patients were finally included, which included 7,231 men and 1,685 women. The median age of the overall population was 65 years. A total of 1,764 patients had distant organ metastases, accounting for $19.8 \%$ of the entire cohort: 462 patients $(5.2 \%)$ had BM, and 1,302 patients (14.6\%) had non-bone organ metastases (liver, lungs, and brain). Table 1 shows the patients' clinical and demographic characteristics. A total of 8916 patients were divided into two groups: $\mathrm{BM}$ and non-BM (NBM). The age in the BM group was lower than that in the NBM group $(60.6 \pm 10.7$ vs. $63.7 \pm 11.1$ years); The $\mathrm{BM}$ group included more male patients $(88.5 \%$ vs. $80.7 \%)$ and more adenocarcinoma cases $(76.6 \%$ vs. $69.7 \%)$ than the NBM group. Patients in the $\mathrm{BM}$ group were more likely to harbor non-bone organ metastases $(52.8 \%$ vs. $12.5 \%)$ and their survival time was shorter $(21.3 \pm 19.8 v v .6 .8 \pm 7.5$ months $)$ than those in the NBM group. In addition, the distribution of the TNM stage also differed between these two groups.

\section{Risk factors of the occurrence of ECBM}

Univariable and multivariable logistic regression results are shown in Table 2, and age was treated as a categorical variable according to the overall population's median age. Univariable logistic regression analysis suggested that age, sex, histology, T stage, G stage, $\mathrm{N}$ stage, and non-bone organ metastasis were associated with ECBM. Incorporating these variables $(\mathrm{P}<0.05)$ into the multivariate logistic regression analysis, it was concluded that there were five independent risk factors of ECBM: age $<65$ years, male sex, stage $\mathrm{T} 1$, advanced $\mathrm{N}$ stage, and non-bone organ metastasis. Specifically, the risk of $\mathrm{BM}$ showed a $30 \%$ reduction in patients aged $\geq 65$ years [odds ratio $(\mathrm{OR})=0.7 ; 95 \%$ confidence interval $(\mathrm{CI}): 0.6-0.9 ; \mathrm{P}<0.001]$. Women were less likely to have $\mathrm{BM}$ than men $(\mathrm{OR}=0.7$; $95 \% \mathrm{CI}$ : 0.5-0.9; $\mathrm{P}=0.012)$. Compared with patients with stage $\mathrm{T} 1$, patients with stages $\mathrm{T} 2(\mathrm{OR}=0.5 ; 95 \% \mathrm{CI}: 0.4-0.8 ; \mathrm{P}=0.003)$ and T3 (OR $=0.6 ; 95 \%$ CI: $0.5-0.8 ; \mathrm{P}<0.001)$ were less likely to develop BM; stage T4 (OR =1.2; 95\% CI: 0.9-1.5; P=0.214) was a predictor for $\mathrm{BM}$, but the $\mathrm{P}$ value was not significant. Compared with patients with stage N0, patients with stages $\mathrm{N} 1$ (OR =1.8; 95\% CI: 1.4-2.3; $\mathrm{P}<0.001)$, N2 (OR =1.9; 95\% CI: $1.4-2.8 ; \mathrm{P}<0.001)$, and N3 (OR $=2.5 ; 95 \%$ CI: 1.6-3.8; $\mathrm{P}<0.001)$ had greater risks of $\mathrm{BM}$. Moreover, the $\mathrm{BM}$ risk in patients with non-bone organ metastases was 
Table 1 Demographic and clinical characteristics of esophageal carcinoma patients with or without bone metastasis

\begin{tabular}{|c|c|c|c|}
\hline \multirow{2}{*}{ Characteristics } & \multicolumn{2}{|c|}{ Bone metastasis } & \multirow{2}{*}{$P$ value } \\
\hline & No & Yes & \\
\hline Age (years) & $63.7 \pm 11.1$ & $60.6 \pm 10.7$ & $<0.001$ \\
\hline Race & & & 0.960 \\
\hline White & 7,253 (85.8) & $398(86.1)$ & \\
\hline Black & $765(9.0)$ & $40(8.7)$ & \\
\hline Other & $436(5.2)$ & $24(5.2)$ & \\
\hline Gender & & & $<0.001$ \\
\hline Male & $6,822(80.7)$ & $409(88.5)$ & \\
\hline Female & 1,632 (19.3) & $53(11.5)$ & \\
\hline Year of diagnosis & & & 0.145 \\
\hline 2010-2012 & 4,137 (48.9) & $210(45.5)$ & \\
\hline 2013-2016 & $4,317(51.1)$ & $252(54.5)$ & \\
\hline Primary tumor site & & & 0.244 \\
\hline Upper & $614(7.3)$ & $24(5.2)$ & \\
\hline Middle & 1,393 (16.5) & $78(16.9)$ & \\
\hline Lower & 6,447 (76.3) & $360(77.9)$ & \\
\hline Histology & & & 0.002 \\
\hline SCC & $2,561(30.3)$ & $108(23.4)$ & \\
\hline$A C$ & $5,893(69.7)$ & $354(76.6)$ & \\
\hline Degree of differentiation & & & $<0.001$ \\
\hline G1 & $593(7.0)$ & $17(3.7)$ & \\
\hline G2 & $3,684(43.6)$ & $145(31.4)$ & \\
\hline G3 & $4,077(48.2)$ & $291(63.0)$ & \\
\hline Undifferentiated & $100(1.2)$ & $9(1.9)$ & \\
\hline T stage & & & $<0.001$ \\
\hline $\mathrm{T} 1$ & $2,478(29.3)$ & $159(34.4)$ & \\
\hline $\mathrm{T} 2$ & $1,115(13.2)$ & $31(6.7)$ & \\
\hline T3 & $3,811(45.1)$ & $148(32.0)$ & \\
\hline $\mathrm{T} 4$ & $1,050(12.4)$ & $124(26.8)$ & \\
\hline $\mathrm{N}$ stage & & & $<0.001$ \\
\hline No & $3,526(41.7)$ & $110(23.8)$ & \\
\hline $\mathrm{N} 1$ & $3,616(42.8)$ & $259(56.1)$ & \\
\hline $\mathrm{N} 2$ & 987 (11.7) & 57 (12.3) & \\
\hline N3 & 325 (3.8) & $36(7.8)$ & \\
\hline
\end{tabular}

Table 1 (continued)
Table 1 (continued)

\begin{tabular}{lccc}
\hline \multirow{2}{*}{ Characteristics } & \multicolumn{2}{c}{ Bone metastasis } & \multirow{2}{*}{ P value } \\
\cline { 2 - 3 } Ro & & \\
\hline No & & & $<.001$ \\
Yes & $2,750(32.5)$ & $198(42.9)$ & \\
Chemotherapy & $5,704(67.5)$ & $264(57.1)$ & \\
No & & & 0.004 \\
Yes & $2,331(27.6)$ & $156(33.8)$ & \\
& $6,123(72.4)$ & $306(66.2)$ &
\end{tabular}

Non-bone organ metastases

$<0.001$

\begin{tabular}{lccc} 
No & $7,396(87.5)$ & $218(47.2)$ & \\
Yes & $1,058(12.5)$ & $244(52.8)$ & \\
Survival, months & $21.3 \pm 19.8$ & $6.8 \pm 7.5$ & $<0.001$ \\
\hline
\end{tabular}

Results in the table are expressed as mean \pm SD or N (\%). SCC, squamous cell cancer; AC, adenocarcinoma.

Table 2 Univariate and multivariate logistic regression analysis for occurrence of bone metastasis in esophageal cancer patients

\begin{tabular}{|c|c|c|c|c|}
\hline \multirow{2}{*}{ Variables } & \multicolumn{2}{|c|}{ Univariable } & \multicolumn{2}{|c|}{ Multivariable } \\
\hline & OR $(95 \% \mathrm{Cl})$ & $P$ & OR $(95 \% \mathrm{Cl})$ & $\mathrm{P}$ \\
\hline \multicolumn{5}{|l|}{ Age } \\
\hline$<65$ years & Reference & & Reference & \\
\hline$\geq 65$ years & $0.6(0.5-0.7)$ & $<0.001$ & $0.7(0.6-0.9)$ & $<0.001$ \\
\hline
\end{tabular}

Race

$\begin{array}{lllll}\text { White } & \text { Reference } & & \text { NA } & \text { NA } \\ \text { Black } & 1.0(0.7-1.3) & 0.777 & \text { NA } & \text { NA } \\ \text { Other } & 1.0(0.7-1.5) & 0.988 & \text { NA } & \text { NA }\end{array}$

Gender

Male Reference Reference

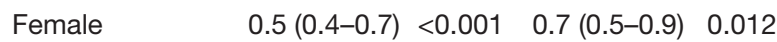

Year of diagnosis

2010-2012 Reference NA NA

2013-2016 $\quad 1.1(1.0-1.4) \quad 0.145 \quad$ NA NA

Primary tumor site

\begin{tabular}{lllll} 
Upper & Reference & & & \\
Middle & $1.4(0.9-2.3)$ & 0.132 & NA & NA \\
Lower & $1.4(0.9-2.2)$ & 0.097 & NA & NA \\
\hline
\end{tabular}

Table 2 (continued) 
Table 2 (continued)

\begin{tabular}{|c|c|c|c|c|}
\hline \multirow{2}{*}{ Variables } & \multicolumn{2}{|c|}{ Univariable } & \multicolumn{2}{|c|}{ Multivariable } \\
\hline & OR (95\% Cl) & $P$ & OR (95\% Cl) & $\mathrm{P}$ \\
\hline
\end{tabular}

Histology

\begin{tabular}{lcccc} 
SCC & Reference & \multicolumn{3}{c}{ Reference } \\
AC & $1.4(1.1-1.8)$ & 0.002 & $1.2(1.0-1.5)$ & 0.118
\end{tabular}

Degree of differentiation

$\begin{array}{lcccc}\text { G1 } & \text { Reference } & \text { Reference } \\ \text { G2 } & 1.4(0.8-2.3) & 0.223 & 1.0(0.6-1.7) & 0.910 \\ \text { G3 } & 2.5(1.5-4.1) & <0.001 & 1.5(0.9-2.5) & 0.124 \\ \text { Undifferentiated } & 3.1(1.4-7.2) & 0.007 & 2.0(0.8-4.9) & 0.111 \\ \text { T stage } & & & & \\ \text { T1 } & \text { Reference } & & \text { Reference } \\ \text { T2 } & 0.4(0.3-0.6)<0.001 & 0.5(0.4-0.8) & 0.003 \\ \text { T3 } & 0.6(0.5-0.8) & <0.001 & 0.6(0.5-0.8) & <0.001 \\ \text { T4 } & 1.8(1.4-2.4) & <0.001 & 1.2(0.9-1.5) & 0.214\end{array}$

$\mathrm{N}$ stage

$\begin{array}{llll}\text { N0 } & \text { Reference } & \text { Reference } \\ \text { N1 } & 2.3(1.8-2.9) & <0.001 & 1.8(1.4-2.3)<0.001 \\ \text { N2 } & 1.9(1.3-2.6)<0.001 & 1.9(1.4-2.8)<0.001 \\ \text { N3 } & 3.6(2.4-5.3)<0.001 & 2.5(1.6-3.8)<0.001\end{array}$

Non-bone organ metastases

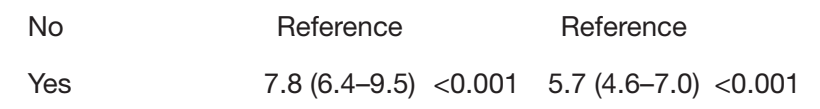

$\mathrm{Cl}$, confidence interval; OR, odds ratio; NA, not available; SCC, squamous cell cancer; $A C$, adenocarcinoma.

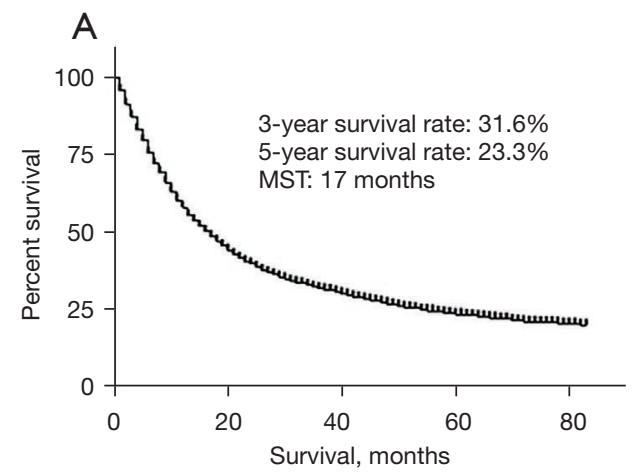

5.7 times that in patients without non-bone organ metastases (OR =5.7; 95\% CI: 4.6-7.0; $\mathrm{P}<0.001)$.

\section{Survival analysis and prognostic factors of ECBM}

The median follow-up time was 14 months (interquartile range, 6-29 months). In the entire cohort (Figure 2A), the MST for the overall population was 17 months, and the 3 - and 5-year survival rates in EC patients were 31.6\% and $23.3 \%$, respectively. In the BM group, the MST was 5 months, and the 3 - and 5 -year survival rates were $2 \%$ and $1 \%$, respectively. In the NBM group, the 3- and 5-year survival rates were $33.2 \%$ and $24.5 \%$, respectively (Figure 2B).

We further conducted Cox regression analysis on data corresponding to $462 \mathrm{ECBM}$ patients (Table 3). These four variables (race, primary tumor site, $\mathrm{G}$ stage, and $\mathrm{N}$ stage) did not meet the proportional hazard assumption; thus, they were not included in the model. The univariate Cox regression model showed that histology, $\mathrm{T}$ stage, nonbone organ metastasis, and therapy were associated with all-cause death. After incorporating these four variables in the multivariate Cox regression model to adjust for confounding effects, it was concluded that adenocarcinoma had a better prognosis than squamous cell carcinoma [hazard ratio $(\mathrm{HR})=0.8 ; 95 \%$ CI: $0.6-1.0 ; \mathrm{P}=0.033$. Compared with patients with stage T1, patients with stage T2 (HR $=0.4 ; 95 \%$ CI: 0.3-0.6; $\mathrm{P}<0.001)$ had a longer survival time, while the $\mathrm{P}$ values for patients with stages $\mathrm{T} 4(\mathrm{HR}=1.2$; 95\% CI: 0.9-1.5; $\mathrm{P}=0.143$ ) and T3 (HR $=0.8$; 95\% CI: $0.7-$ $1.1 ; \mathrm{P}=0.151)$ were not significant. Patients with non-bone organ metastases had a higher risk of all-cause death (HR $=1.6$; 95\% CI: $1.3-1.9 ; \mathrm{P}<0.001)$. Compared with patients

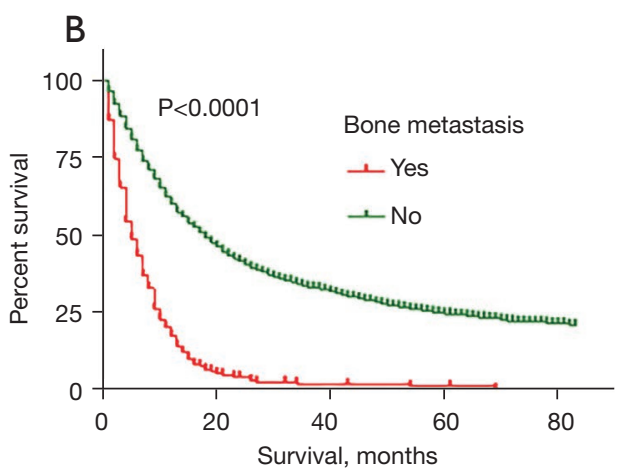

Figure 2 Kaplan-Meier curve of overall survival among esophageal carcinoma patients: (A) in entire cohort, (B) stratified by bone metastasis. 
Table 3 Univariate and multivariate COX regression analysis for prognostic factors associated with all-cause death in bone metastasis patients

\begin{tabular}{|c|c|c|c|c|}
\hline \multirow{2}{*}{ Variables } & \multicolumn{2}{|c|}{ Univariable } & \multicolumn{2}{|c|}{ Multivariable } \\
\hline & $\mathrm{HR}(95 \% \mathrm{Cl})$ & $\mathrm{P}$ & $\mathrm{HR}(95 \% \mathrm{Cl})$ & $\mathrm{P}$ \\
\hline \multicolumn{5}{|l|}{ Age } \\
\hline$<65$ years & Reference & & NA & NA \\
\hline$\geq 65$ years & $1.2(1.0-1.4)$ & 0.097 & NA & NA \\
\hline \multicolumn{5}{|l|}{ Race } \\
\hline White & NA & NA & NA & NA \\
\hline Black & NA & NA & NA & NA \\
\hline Other & NA & NA & NA & NA \\
\hline \multicolumn{5}{|l|}{ Gender } \\
\hline Male & Reference & & NA & NA \\
\hline Female & $0.8(0.6-1.1)$ & 0.192 & NA & NA \\
\hline \multicolumn{5}{|c|}{ Year of diagnosis } \\
\hline 2010-2012 & Reference & & NA & NA \\
\hline 2013-2016 & $1.1(0.9-1.4)$ & 0.231 & NA & NA \\
\hline \multicolumn{5}{|c|}{ Primary tumor site } \\
\hline Upper & NA & & & \\
\hline Middle & NA & & NA & NA \\
\hline Lower & NA & & NA & NA \\
\hline \multicolumn{5}{|l|}{ Histology } \\
\hline SCC & Reference & & Reference & \\
\hline$A C$ & $0.7(0.6-0.9)$ & 0.005 & $0.8(0.6-1.0)$ & 0.033 \\
\hline
\end{tabular}

Degree of differentiation

$\begin{array}{lcccc}\text { G1 } & \text { NA } & \text { NA } & \text { NA } & \text { NA } \\ \text { G2 } & \text { NA } & \text { NA } & \text { NA } & \text { NA } \\ \text { G3 } & \text { NA } & \text { NA } & \text { NA } & \text { NA } \\ \text { Undifferentiated } & \text { NA } & \text { NA } & \text { NA } & \text { NA } \\ \text { T stage } & & & & \\ \text { T1 } & \text { Reference } & & \text { Reference } & \\ \text { T2 } & 0.5(0.3-0.7) & <0.001 & 0.4(0.3-0.6) & <0.001 \\ \text { T3 } & 0.8(0.6-1.0) & 0.035 & 0.8(0.7-1.1) & 0.151 \\ \text { T4 } & 1.2(0.9-1.5) & 0.169 & 1.2(0.9-1.5) & 0.143\end{array}$

$\mathrm{N}$ stage

\begin{tabular}{lllll} 
N0 & NA & NA & NA & NA \\
N1 & NA & NA & NA & NA \\
N2 & NA & NA & NA & NA \\
N3 & NA & NA & NA & NA \\
\hline
\end{tabular}

Table 3 (continued)
Table 3 (continued)

\begin{tabular}{lccccc}
\hline \multirow{2}{*}{ Variables } & \multicolumn{2}{c}{ Univariable } & & \multicolumn{2}{c}{ Multivariable } \\
\cline { 2 - 2 } \cline { 5 - 6 } Non-bone organ metastases & & & \\
No & reference & & reference & \\
Yes & $1.5(1.3-1.9)$ & $<0.001$ & & $1.6(1.3-1.9)$ & $<0.001$ \\
Adjuvant therapy & & & & \\
No & Reference & & Reference & \\
Radiotherapy & $0.6(0.5-0.9)$ & 0.003 & & $0.7(0.5-0.9)$ & 0.015 \\
Chemotherapy & $0.3(0.2-0.4)$ & $<0.001$ & & $0.3(0.2-0.3)$ & $<0.001$ \\
Combined & $0.2(0.2-0.3)$ & $<0.001$ & $0.2(0.2-0.3)$ & $<0.001$ \\
\hline
\end{tabular}

$\mathrm{Cl}$, confidence interval; OR, odds ratio; NA, not available; SCC, squamous cell cancer; AC, adenocarcinoma; combined, combined radiotherapy and chemotherapy.

without treatment, patients who received radiotherapy alone (HR $=0.7 ; 95 \%$ CI: $0.5-0.9 ; \mathrm{P}=0.015)$, chemotherapy alone (HR $=0.3 ; 95 \%$ CI: $0.2-0.3 ; \mathrm{P}<0.001)$, and combined radiotherapy and chemotherapy ( $\mathrm{HR}=0.2 ; 95 \% \mathrm{CI}: 0.2-0.3$; $\mathrm{P}<0.001)$ had better prognosis. The survival assessment in ECBM patients stratified by histology, T stage, non-bone metastases, and therapy is displayed in Figure 3.

Among 462 ECBM patients, 78 received no treatment, 78 received radiotherapy alone, 120 received chemotherapy alone, and 186 received combined radiotherapy and chemotherapy; Kaplan-Meier analysis (Figure 3D) showed that the MSTs were 1, 3, 6, and 8 months, respectively. The combination of radiotherapy and chemotherapy was associated with an improved MST in patients with ECBM by 7 months.

In univariable Fine and Gray's competing risk analysis (Table 4), we obtained results consistent with those of Cox regression analysis: histology, $\mathrm{T}$ stage, non-bone organ metastases, and therapy were associated with cancer-specific death. After including these four variables in multivariate competing analysis to adjust for confounding effects, the effect of different histological types on prognosis was found to be statistically insignificant (HR $=0.80$; 95\% CI: $0.63-$ $1.02 ; \mathrm{P}=0.076)$. Compared with the prognosis in patients with stage T1 ECBM, patients with stage T2 ECBM had a better prognosis ( $\mathrm{HR}=0.48$; 95\% CI: $0.31-0.72 ; \mathrm{P}<0.01$ ), while the HRs for stages T3 and T4 were not statistically significant. Non-bone organ metastases were associated with an increased risk of cancer-specific death ( $\mathrm{HR}=1.58 ; 95 \%$ CI: $1.28-1.94 ; \mathrm{P}<0.01)$; chemotherapy alone $(\mathrm{HR}=0.31$; 

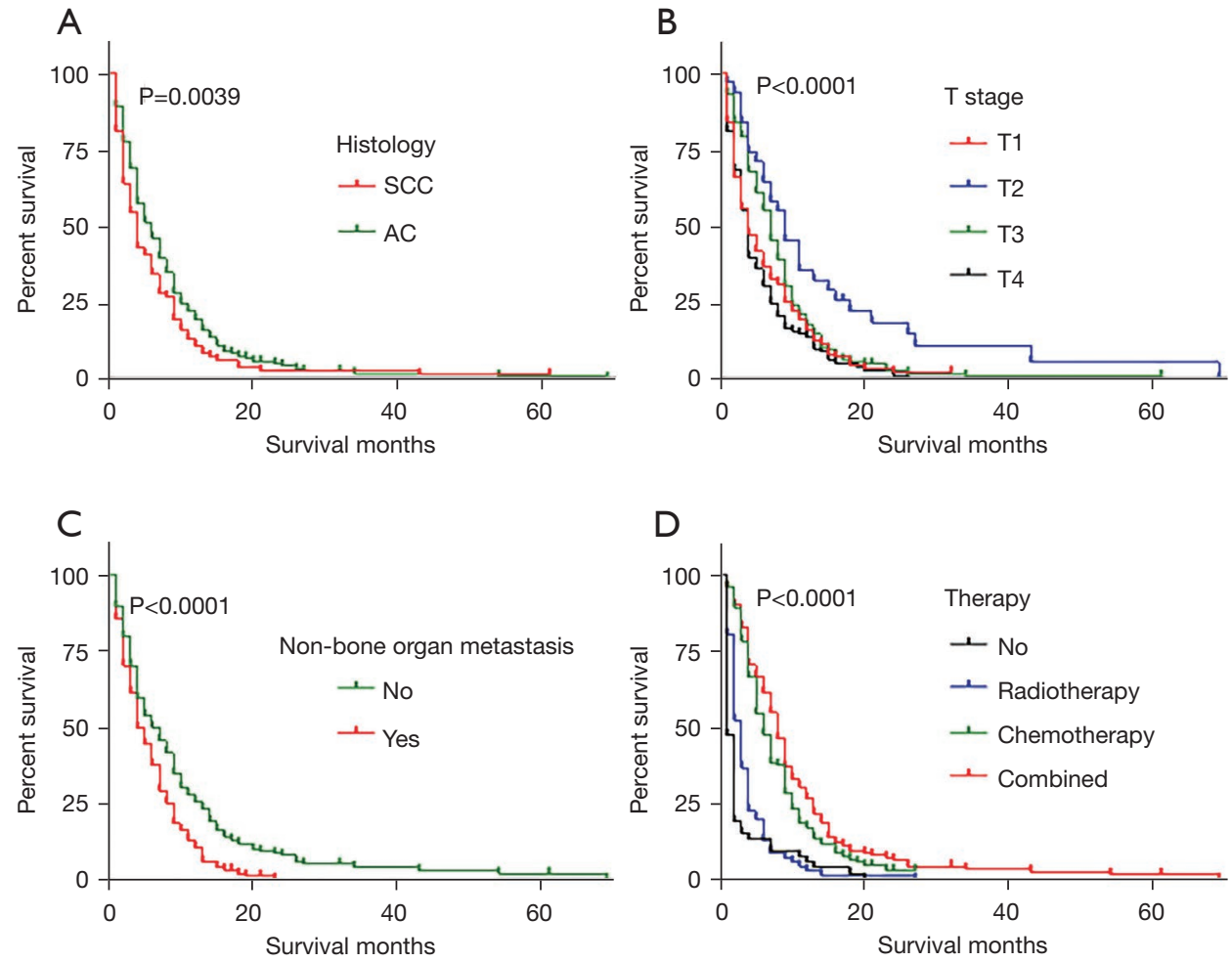

Figure 3 Kaplan-Meier analysis of overall survival among esophageal carcinoma patients with bone metastasis: (A) stratified by histology, (B) stratified by $\mathrm{T}$ stage, (C) stratified by non-bone organ metastasis, (D) stratified by therapy. SCC, squamous cell carcinoma; AC, adenocarcinoma.

95\% CI: $0.22-0.43 ; \mathrm{P}<0.01)$ and combined radiotherapy and chemotherapy (HR $=0.27 ; 95 \%$ CI: $0.20-0.37 ; \mathrm{P}<0.01$ ) were associated with better survival benefits than those in patients who did not receive any treatment, and the $\mathrm{P}$ value of the HR for radiotherapy alone was insignificant.

\section{Discussion}

Although the incidence of EC is low, it has always been a challenge encountered by thoracic surgeons because of its poor prognosis (10). Currently, the major treatment is radical surgery plus adjuvant radiotherapy and chemotherapy, while distant metastases often make surgery not available (11). It has been reported that the most common metastasis sites are sequentially the liver, lungs, bone, and brain, and BM accounts for $7.7 \%$ of the population (6). In this study, we found that $19.8 \%$ of patients had distant organ metastases: $5.2 \%$ with $\mathrm{BM}$, and $14.6 \%$ with non-bone organ metastases. The most common liver and lung metastases of EC have been described in detail in recent reports, but research on ECBM is rare due to its relatively low incidence. Katagiri et al. prospectively analyzed BM in 958 patients with different malignancies and identified six factors influencing prognosis: the primary lesion, visceral or cerebral metastases, abnormal laboratory data, poor performance status, previous chemotherapy, and multiple skeletal metastases (12). Imura et al. retrospectively studied $58 \mathrm{EC}$ patients in a single center, 14 of whom had BM. The main conclusion of their study was that high serum carcinoembryonic antigen levels and not receiving chemotherapy are risk factors of poor prognosis (13). However, this study focused on exploring the relationship between serological indicators and survival time, and the sample size was not sufficiently large. Zhang et al. studied the data of ECBM patients from the SEER database, but they incorporated EC cases that did not involve first primary tumors, and the competing risks of non-cancerrelated death may have affected the results. Moreover, their analysis did not include the effect of chemoradiotherapy on prognosis (9). We avoided these limitations and only included cases of EC diagnosed as the first primary tumor, rendering the results more convincing. 
Table 4 Univariate and multivariate competing risk analysis for prognostic factors associated with cancer-specific death in bone metastasis patients

\begin{tabular}{|c|c|c|c|c|}
\hline \multirow{2}{*}{ Variables } & \multicolumn{2}{|l|}{ Univariable } & \multicolumn{2}{|c|}{ Multivariable } \\
\hline & $\mathrm{HR}(95 \% \mathrm{Cl})$ & $P$ & HR (95\% Cl) & $\mathrm{P}$ \\
\hline \multicolumn{5}{|l|}{ Age } \\
\hline$<65$ years & Reference & & & \\
\hline$\geq 65$ years & $1.12(0.91-1.36)$ & 0.283 & & \\
\hline \multicolumn{5}{|l|}{ Race } \\
\hline White & Reference & & & \\
\hline Black & $1.10(0.78-1.56)$ & 0.571 & & \\
\hline Other & $1.08(0.69-1.68)$ & 0.740 & & \\
\hline \multicolumn{5}{|l|}{ Gender } \\
\hline Male & Reference & & & \\
\hline Female & $0.80(0.59-1.09)$ & 0.165 & & \\
\hline
\end{tabular}

Year of diagnosis

\begin{tabular}{|c|c|}
\hline 2010-2012 & Reference \\
\hline 2013-2016 & $1.12(0.92-1.37) 0.251$ \\
\hline
\end{tabular}

Primary tumor site

$\begin{array}{ccc}\text { Upper } & \text { Reference } \\ \text { Middle } & 0.88(0.53-1.46) & 0.619 \\ \text { Lower } & 0.85(0.54-1.36) & 0.502\end{array}$

Histology

\begin{tabular}{|c|c|c|}
\hline $\operatorname{SCC}$ & Reference & Reference \\
\hline$A C$ & $0.77(0.61-0.98)$ & $<0.05 \quad 0.80(0.63-1.02) 0.076$ \\
\hline
\end{tabular}

Degree of differentiation

\begin{tabular}{|c|c|c|c|}
\hline G1 & Reference & & \\
\hline G2 & $1.07(0.63-1.83)$ & 0.801 & \\
\hline G3 & $1.38(0.82-2.32)$ & 0.227 & \\
\hline Undifferentiated & $1.86(0.81-4.26)$ & 0.141 & \\
\hline \multicolumn{4}{|l|}{ T stage } \\
\hline $\mathrm{T} 1$ & Reference & & Reference \\
\hline $\mathrm{T} 2$ & $0.54(0.36-0.82)$ & $<0.01$ & $0.48(0.31-0.72)<0.01$ \\
\hline T3 & $0.79(0.62-1.01)$ & 0.057 & $0.84(0.65-1.07) 0.148$ \\
\hline $\mathrm{T} 4$ & $1.15(0.89-1.49)$ & 0.279 & $1.16(0.90-1.50) 0.262$ \\
\hline \multicolumn{4}{|l|}{$\mathrm{N}$ stage } \\
\hline No & Reference & & \\
\hline N1 & $1.16(0.90-1.48)$ & 0.251 & \\
\hline N2 & $1.05(0.74-1.49)$ & 0.766 & \\
\hline N3 & $1.18(0.77-1.81)$ & 0.455 & \\
\hline
\end{tabular}

Table 4 (continued)
Table 4 (continued)

\begin{tabular}{|c|c|c|c|c|}
\hline \multirow{2}{*}{ Variables } & \multicolumn{2}{|l|}{ Univariable } & \multicolumn{2}{|c|}{ Multivariable } \\
\hline & $\mathrm{HR}(95 \% \mathrm{Cl})$ & $\mathrm{P}$ & $\mathrm{HR}(95 \% \mathrm{Cl})$ & $P$ \\
\hline \multicolumn{5}{|c|}{ Non-bone organ metastasis } \\
\hline No & Reference & & Reference & \\
\hline Yes & $1.54(1.25-1.88)$ & $<0.01$ & $1.58(1.28-1.94)$ & $<0.01$ \\
\hline \multicolumn{5}{|l|}{ Adjuvant therapy } \\
\hline No & Reference & & Reference & \\
\hline Radiotherapy & $0.76(0.53-1.09)$ & 0.131 & $0.81(0.56-1.17)$ & 0.257 \\
\hline Chemotherapy & $0.33(0.24-0.46)$ & $<0.01$ & $0.31(0.22-0.43)$ & $<0.01$ \\
\hline Combined & $0.27(0.20-0.37)$ & $<0.01$ & $0.27(0.20-0.37)$ & $<0.01$ \\
\hline
\end{tabular}

$\mathrm{Cl}$, confidence interval; OR, odds ratio; SCC, squamous cell cancer; AC, adenocarcinoma; combined, combined radiotherapy and chemotherapy.

Even in the United States, a developed country, the overall 5 -year survival rate for EC is less than $20 \%$ (4). For metastatic EC, the overall survival time is only approximately $8-10$ months, and the 5 -year survival rate is notably low at $5 \%$ (14). In our study cohort, the MST was 17 months for EC patients, and the 3- and 5-year survival rates were $31.6 \%$ and $23.3 \%$, respectively, which are slightly higher than previously reported data. The 3- and 5-year survival rates in the NBM group were $33.2 \%$ and $24.5 \%$, respectively, and those in the BM group were $2 \%$ and $1 \%$, respectively. BM was associated with a decreased survival time in patients, posing a great threat to their lives.

It is necessary to determine the predictors of distant metastases of EC because this may help doctors recognize high-risk patients and arrange subsequent examinations or treatment. This study identified five independent risk factors of ECBM: age $<65$ years, male sex, stage T1, advanced $\mathrm{N}$ stage, and non-bone organ metastases. Based on previous studies, the independent risk factors for liver metastasis of EC include age (younger), primary tumor site (middle and lower segments), degree of differentiation (poor), histology (adenocarcinoma), T stage (T1), N stage (advanced), and extrahepatic organ metastases (7). Meanwhile, the independent risk factors for lung metastasis of EC include the degree of differentiation (poor), histology (squamous cell carcinoma), $\mathrm{T}$ stage (T1 and $\mathrm{T} 4$ ), $\mathrm{N}$ stage (advanced), race (black), and non-lung organ metastases (8). Combined with the results of this study, these findings can be summarized as follows: Young patients are more likely to develop liver metastasis and BM; Sex is not associated with 
lung or liver metastases; Patients with poor differentiation are prone to liver and lung metastases; Adenocarcinoma is prone to liver metastasis, and squamous cell carcinoma is prone to lung metastasis, while histology is not associated with $\mathrm{BM}$, which is consistent with the results of a previous study (15). Their study demonstrated that adenocarcinoma and squamous cell carcinoma did not differ in ECBM, and patients with stage $\mathrm{T} 1$ are more likely to have organ metastases (liver, lung, and bone) than those in patients with stages $\mathrm{T} 2$ and $\mathrm{T} 3$.

Considering the poor prognosis of patients with distant metastases, it is important to investigate factors affecting the prognosis of patients with distant metastases. We conducted Cox regression and competing risk regression to analyze the factors associated with all-cause and cancerspecific death, respectively. Cox regression identified four factors that were associated with an increased risk of allcause death in ECBM patients: squamous cell carcinoma, stages $\mathrm{T} 1$ and $\mathrm{T} 4$, non-bone organ metastases, and the lack of treatment. The competing risk model was implemented to explore the factors associated with cancer-specific death: T stage, non-bone metastases, and therapy. After defining non-cancer-related deaths as different endpoints, different histological types did not differ in prognosis among ECBM patients. However, the results obtained from the two models are largely concordant, indicating that the statistical analyses are stable and reliable. According to recent reports, the following factors are associated with an increased risk of all-cause death in patients with liver metastasis: sex (male), age (advanced), histology (squamous cell carcinoma), other organ metastases, and therapy (no treatment) (7). In patients with lung metastasis, the following factors are associated with increased all-cause death: age (advanced), non-lung organ metastases, and therapy (no treatment) (8). In summary, age is mainly related to the prognosis of liver and lung metastases. Squamous cell carcinoma leads to a poor prognosis in patients with liver metastasis and BM; Combined radiotherapy and chemotherapy results in better survival benefits than chemotherapy or radiotherapy alone for EC patients with distant organ metastases. In addition, it is worth noting that patients with stages T1 and T4 ECBM have a worse prognosis than patients with stages $\mathrm{T} 2$ and T3 ECBM.

Therefore, stage T1 not only renders EC patients prone to $\mathrm{BM}$, but also results in a poor prognosis in ECBM. This is consistent with the results of previous studies (16). In the TNM staging of EC, T staging refers to the depth of tumor invasion. Although stage T1 tumors have a shallow depth of infiltration, their outcomes are worse when compared to stage $\mathrm{T} 2$ and $\mathrm{T} 3$ tumors, and this result is different from the association between the $\mathrm{N}$ stage and BM. Cai et al. retrospectively analyzed 3,013 patients with gallbladder cancer and concluded that stage $\mathrm{T} 1$ has a higher risk of distant metastasis than that associated with stage T2 (17). Guo et al. studied 212,787 patients with colorectal cancer and found that stage $\mathrm{T} 1$ is more prone to $\mathrm{BM}$ than stages $\mathrm{T} 2$, $\mathrm{T} 3$, and $\mathrm{T} 4$. Besides, survival time of stage $\mathrm{T} 1$ is worse than other advanced $\mathrm{T}$ stage in $\mathrm{BM}$ patients (18), and $\mathrm{T}$ stage also represents the depth of invasion in gallbladder and colorectal cancer. The results are partly consistent with research in prostate cancer (19), but not for uterine cervical cancer (20). Limited by current advances in esophageal cancer study, the intrinsic mechanism by which patients with stage T1 are prone to distant metastases compared to patients with deeper invasion remains unclear, and the reason why stage $\mathrm{T} 1$ tumors have a shorter survival time than $\mathrm{T} 2$ is also not clear after consulting a lot of literatures. The contradiction in stage T1 may partly due to the sample size and single data source, but further fundamental researches are needed to verify and reveal it. This population-based clinical study may help to screen and early identify highrisk patients with $\mathrm{BM}$, while second-generation sequencing technology and disease molecular mechanism research make identifying disease-related specific mutations possible, which could promote the development of precision medicine.

At present, there remain some controversies regarding the optimal therapy for EC patients with distant metastases. Wu et al. advocated the use of radiotherapy plus surgery (14), and $\mathrm{Ku}$ et al. suggested that a combination of radiotherapy and chemotherapy should be adopted (21). However, these results have not been confirmed in a large sample of the population. The National Comprehensive Cancer Network guidelines indicate that palliative/best supportive treatment should be adopted for these patients with advanced-cancer symptoms, such as dysphagia, obstruction, pain, and bleeding, the corresponding remission therapy should be used (22). Previous retrospective studies based on the SEER database have shown that the optimal therapy for EC patients with lung and liver metastases is combined radiotherapy and chemotherapy $(7,8)$. In this study, the Kaplan-Meier curve analysis showed that combined radiotherapy and chemotherapy improved the patients' MST by 7 months. In addition, the results of the multivariate Cox regression and competing risk analysis are consistent with the results of the Kaplan-Meier curve 
analysis: combined radiotherapy and chemotherapy have the best prognostic benefits. In conclusion, the best treatment for with EC patients with distant organ metastases is combined radiotherapy and chemotherapy.

This study had some limitations. First, the SEER database only contains data corresponding to EC patients in the United States, and cases from other regions are not available. Second, the SEER database only records the initial diagnosis of $\mathrm{BM}$ in EC patients; therefore, the true rate of BM may be underestimated. Third, it is inevitable that retrospective studies have lost to follow-up bias and information bias. Lastly, the type and dosage of drugs in chemotherapy and intensity of irradiation in radiotherapy have not been explained.

\section{Conclusions}

$\mathrm{BM}$ is rare in EC patients, but its prognosis is poor. This study identified independent risk factors for the development of BM and prognostic factors related to all-cause and cancer-specific death. These findings may help distinguish high-risk patients with $\mathrm{BM}$ and evaluate prognosis in ECBM patients. It is worth noting that stage $\mathrm{T} 1$ and non-bone organ metastasis are not only associated with an increased risk of BM, but also impair prognosis in ECBM patients. In addition, combined radiotherapy and chemotherapy should be advocated to improve the MST in ECBM patients from 1 to 8 months.

\section{Acknowledgments}

Funding: None.

\section{Footnote}

Reporting Checklist: The authors have completed the STROBE reporting checklist. Available at https://tcr. amegroups.com/article/view/10.21037/tcr-21-2104/rc

Conflicts of Interest: All authors have completed the ICMJE uniform disclosure form (available at https://tcr.amegroups. com/article/view/10.21037/tcr-21-2104/coif). The authors have no conflicts of interest to declare.

Ethical Statement: The authors are accountable for all aspects of the work in ensuring that questions related to the accuracy or integrity of any part of the work are appropriately investigated and resolved. The study was conducted in accordance with the Declaration of Helsinki (as revised in 2013). Since all the data used in the study were from public databases, the requirement to obtain informed consent from the patients was exempted.

Open Access Statement: This is an Open Access article distributed in accordance with the Creative Commons Attribution-NonCommercial-NoDerivs 4.0 International License (CC BY-NC-ND 4.0), which permits the noncommercial replication and distribution of the article with the strict proviso that no changes or edits are made and the original work is properly cited (including links to both the formal publication through the relevant DOI and the license). See: https://creativecommons.org/licenses/by-nc-nd/4.0/.

\section{References}

1. Sung H, Ferlay J, Siegel RL, et al. Global Cancer Statistics 2020: GLOBOCAN Estimates of Incidence and Mortality Worldwide for 36 Cancers in 185 Countries. CA Cancer J Clin 2021;71:209-49.

2. Ohashi S, Miyamoto S, Kikuchi O, et al. Recent Advances From Basic and Clinical Studies of Esophageal Squamous Cell Carcinoma. Gastroenterology 2015;149:1700-15.

3. Tanaka T, Fujita H, Matono S, et al. Outcomes of multimodality therapy for stage IVB esophageal cancer with distant organ metastasis (M1-Org). Dis Esophagus 2010;23:646-51.

4. Rustgi AK, El-Serag HB. Esophageal carcinoma. N Engl J Med 2014;371:2499-509.

5. Tang X, Zhou X, Li Y, et al. A Novel Nomogram and Risk Classification System Predicting the Cancer-Specific Survival of Patients with Initially Diagnosed Metastatic Esophageal Cancer: A SEER-Based Study. Ann Surg Oncol 2019;26:321-8.

6. Ai D, Zhu H, Ren W, et al. Patterns of distant organ metastases in esophageal cancer: a population-based study. J Thorac Dis 2017;9:3023-30.

7. Li H, Zhang S, Guo J, et al. Hepatic Metastasis in Newly Diagnosed Esophageal Cancer: A Population-Based Study. Front Oncol 2021;11:644860.

8. Guo J, Zhang S, Li H, et al. Lung Metastases in Newly Diagnosed Esophageal Cancer: A Population-Based Study. Front Oncol 2021;11:603953.

9. Zhang J, Ma W, $\mathrm{Wu} \mathrm{H}$, et al. Analysis of Homogeneous and Heterogeneous Factors for Bone Metastasis in Esophageal Cancer. Med Sci Monit 2019;25:9416-25.

10. Smyth EC, Lagergren J, Fitzgerald RC, et al. Oesophageal 
cancer. Nat Rev Dis Primers 2017;3:17048.

11. Lagergren J, Smyth E, Cunningham D, et al. Oesophageal cancer. Lancet 2017;390:2383-96.

12. Katagiri H, Okada R, Takagi T, et al. New prognostic factors and scoring system for patients with skeletal metastasis. Cancer Med 2014;3:1359-67.

13. Imura Y, Yamamoto S, Wakamatsu T, et al. Clinical features and prognostic factors in patients with esophageal cancer with bone metastasis. Oncol Lett 2020;19:717-24.

14. Wu SG, Xie WH, Zhang ZQ, et al. Surgery Combined with Radiotherapy Improved Survival in Metastatic Esophageal Cancer in a Surveillance Epidemiology and End Results Population-based Study. Sci Rep 2016;6:28280.

15. Wu SG, Zhang WW, Sun JY, et al. Patterns of Distant Metastasis Between Histological Types in Esophageal Cancer. Front Oncol 2018;8:302.

16. Liu M, Wang C, Gao L, et al. A nomogram to predict long-time survival for patients with $\mathrm{M} 1$ diseases of esophageal cancer. J Cancer 2018;9:3986-90.

17. Cai YL, Lin YX, Jiang LS, et al. A Novel Nomogram Predicting Distant Metastasis in T1 and T2 Gallbladder
Cancer: A SEER-based Study. Int J Med Sci 2020;17:1704-12.

18. Guo X, Zhang C, Ma W, et al. Patterns of bone metastases in newly diagnosed colorectal cancer: a realworld analysis in the SEER database. Int J Colorectal Dis 2019;34:533-43.

19. Guo X, Zhang C, Guo Q, et al. The homogeneous and heterogeneous risk factors for the morbidity and prognosis of bone metastasis in patients with prostate cancer. Cancer Manag Res 2018;10:1639-46.

20. Zhang Y, Guo X, Wang G, et al. Real-World Study of the Incidence, Risk Factors, and Prognostic Factors Associated with Bone Metastases in Women with Uterine Cervical Cancer Using Surveillance, Epidemiology, and End Results (SEER) Data Analysis. Med Sci Monit 2018;24:6387-97.

21. Ku GY. Systemic therapy for esophageal cancer: chemotherapy. Chin Clin Oncol 2017;6:49.

22. Ajani JA, D'Amico TA, Bentrem DJ, et al. Esophageal and Esophagogastric Junction Cancers, Version 2.2019, NCCN Clinical Practice Guidelines in Oncology. J Natl Compr Canc Netw 2019;17:855-83.
Cite this article as: Wang RC, Liu XL, Qi C, Chen H, Liu YY, Li DM, Song HZ, Yi J. Bone metastasis of esophageal carcinoma diagnosed as a first primary tumor: a population-based study. Transl Cancer Res 2022;11(1):113-123. doi: 10.21037/tcr-21-2104 